\title{
Los derechos de la naturaleza en diálogo intercultural: una mirada a la jurisprudencia sobre los páramos andinos y los glaciares indios
}

\author{
The rights of nature in intercultural dialogue: \\ a look at jurisprudence on the Andean páramos \\ and Indian glaciers \\ Adriana Rodríguez Caguana \\ Universidad Andina Simón Bolívar \\ adriana.rodriguez@uasb.edu.ec \\ Viviana Morales Naranjo \\ Universidad de las Américas \\ vivianamoralesnaranjo@outlook.fr
}

doi: http://dx.doi.org/10.18543/djhr.1909

Cómo citar/Citation: Rodríguez Caguana, Adriana y Viviana Morales. 2020. «Los derechos de la naturaleza en diálogo intercultural: una mirada a la jurisprudencia sobre los páramos andinos y los glaciares indios». Deusto Journal of Human Rights, No. 6: 99-123. doi: http://dx.doi.org/10.18543/djhr. 1909

Sumario: Introducción. 1. El ecocentrismo y el bioculturalismo: dos enfoques para decolonizar la modernidad. 2. El desarrollo de los derechos bioculturales, los derechos de participación y los derechos de la naturaleza en Colombia. 2.1. Los derechos bioculturales como medio para vincular la cultura y la biodiversidad. 2.2. El derecho a la participación comunitaria como herramienta para proteger la naturaleza. 2.3. El reconocimiento de los páramos y sus fuentes de agua como sujetos de derechos. 3. La protección de los páramos en Ecuador a través de los derechos de la naturaleza y los derechos de participación. 3.1. El limitado avance de los derechos de la naturaleza en Ecuador. 3.2. La protección a los páramos a través de la aplicación de los derechos de participación. 4. La protección de los Himalayas de la India a través de los derechos de la naturaleza. Conclusiones. Bibliografía.

Resumen: Las montañas de los Andes y del Himalaya poseen características bioculturales en común, ya que son fuentes de agua en territorios biodiversos y albergan a miles de familias campesinas e indígenas; 
sin embargo, ambas se encuentran en situación de eminente peligro por el extractivismo a gran escala. De ahí que las altas Cortes de Ecuador, Colombia y La India se vieron obligadas a pronunciarse frente a la crisis ecológica y cultural a la que se enfrentan sus sistemas montañosos. Para esto, construyeron una argumentación pluralista basada en el reconocimiento de los derechos de la naturaleza. Con el enfoque del concepto de interculturalidad, se analizará críticamente la jurisprudencia de estos tres Estados biodiversos y fuertemente impactados por las actividades antropocéntricas. Además, esta investigación evidenciará la importancia de desarrollar el contenido de los derechos de la naturaleza y los derechos de participación comunitaria desde la perspectiva biocultural1'.

Palabras clave: páramos, glaciares, bioculturalidad, derechos de la naturaleza, participación.

Abstract: The Andes and Himalayan mountain ranges have biocultural characteristics in common, as they are sources of water in biodiverse territories and are home to thousands of peasant and indigenous families. However, they are in evident danger due to large-scale extractivism. Hence, the high courts of Ecuador, Colombia and India felt compelled to pass new legislation in the face of the ecological and cultural crisis facing their mountain ranges. From an intercultural approach, the jurisprudence of these three biodiverse States, which have been strongly impacted by anthropocentric activities, will be critically analysed. In addition, this article will also demonstrate the importance of developing the content of the rights of nature and the rights of community participation from a biocultural perspective.

Keywords: moors, glaciers, bioculturality, rights of nature, participation.

1 Este artículo forma parte de los resultados de la investigación «Los fundamentos interculturales sobre los derechos de la naturaleza en la jurisprudencia de las altas Cortes de Ecuador, la India y Colombia», financiada por el Fondo de Investigaciones de la Universidad Andina Simón Bolívar, sede Ecuador, año 2019. 


\section{Introducción}

La modernidad, de acuerdo con Bolívar Echeverría, se desarrolló a partir del siglo XV en Europa, cuando el secreto de la productividad del trabajo humano dio origen a las correspondientes innovaciones técnicas de producción, como la navegación que permitió la expansión del sistema de explotación a gran escala. A partir de entonces, desde la lógica capitalista, opuesta a otros entendimientos posibles de socialización humana, nada se produce, nada se consume, ningún valor de uso puede realizarse en la vida práctica de la sociedad, si no se encuentra en función de soporte o vehículo de la valorización del valor y de la acumulación (Echeverría 2009, 1-16).

De esta forma, la modernidad hegemónica apuesta por un racionalismo científico, como forma exclusiva de conocimiento; por el capitalismo, como forma de relacionamiento humano; por la colonialidad, como mecanismo de imposición cultural; y, por la colonización, como forma de ejercicio del poder (Ávila 2019, 136-137). Por lo tanto, la naturaleza deja de ser vista como un elemento con un valor intrínseco para considerarla como una mercancía que puede ser objeto de explotación. Esta modernidad impuso la idea de que las altas montañas no son valiosas por la biodiversidad que poseen o por la cantidad de agua que proveen, sino por los minerales que tienen para ser extraídos y cuán fértil es su suelo para promover la ganadería, la agricultura extensiva y, en el caso de las zonas andinas, la plantación de árboles, como eucalipto y pinos (Serrano y Galárraga 2015, 380-382).

Los pueblos indígenas y comunidades campesinas han defendido permanentemente su derecho a salvaguardar sus territorios, que es el lugar de intercambio entre humanos y naturaleza para satisfacer las necesidades productivas y reproductivas de una colectividad, pero en función de sus prioridades culturales (Surrallés 2009, 29-45). Para los habitantes de los páramos, cada uno de los elementos naturales permiten construir y consolidar su cohesión social y cultura. Las prácticas mercantilistas no son un problema aislado de los países latinoamericanos: la modernidad hegemónica pone en riesgo la conservación de todos los ecosistemas biodiversos y a las poblaciones que en ellos habitan. De esta forma, las altas montañas están siendo afectadas por las actividades extractivas, como la deforestación, el tráfico de animales y el turismo a gran escala; la actividad minera es la que más impacto ambiental negativo genera (Tapia 2019, 44-47).

No obstante esta realidad, el proyecto de mercantilización no ha sido fácil, los colectivos organizados han generado procesos de resistencias que visibilizan otras formas de relacionarse con los 
territorios biodiversos y se han convertido en guardianes de los derechos de la naturaleza. Por tal motivo, es indispensable un tipo de justicia intercultural, generador de puentes comunicativos entre las normas constitucionales vigentes y la reivindicación de los pueblos afectados. Además, frente a la expropiación de saberes, la represión cultural y la imposición del racionalismo mercantilista colonial (Quijano 2000, 209) es necesario que los Estados democráticos garanticen la protección de tres derechos que se encuentran estrechamente relacionados: los derechos de la naturaleza, los derechos bioculturales y los derechos de participación comunitaria.

Desde esta perspectiva, es indispensable que las cortes transiten hacia la construcción de lo que Walsh $(2009,28)$ denomina un «constitucionalismo interculturalizado» bajo el cual la naturaleza es vista como un ser vivo, con inteligencia, sentimientos y espiritualidad. Por tal motivo, esta investigación se basa en el análisis a la jurisprudencia más significativa de las altas Cortes de tres países que han desarrollado los derechos de la naturaleza en distintas dimensiones. En primer lugar, Colombia ha emitido decisiones en las que se reconocen los derechos de la naturaleza de forma general o de ciertos elementos específicos de protección a los ecosistemas. En segundo lugar, Ecuador es el primer país del mundo en reconocer los derechos de la naturaleza, en el que sus altas Cortes están obligadas a tomar en cuenta el enfoque ecocéntrico que atraviesa a la norma suprema. Finalmente, la India posee un nutrido desarrollo jurisprudencial que explicita los vínculos entre los colectivos religiosos y sus territorios sagrados. Las siguientes líneas nos permitirán comprender si los jueces están resolviendo los conflictos con un enfoque intercultural, que reconoce las relaciones bioculturales de los colectivos. Para encaminar el estudio se recurrirá al desarrollo teórico de la hermenéutica intercultural del Sur y los estudios socio-ambientales (Walsh 2009; Fornet-Betancourt 2002 y 2006, y Leff 2002).

\section{El ecocentrismo y el bioculturalismo: dos enfoques para decolonizar la modernidad}

A pesar del continuo perjuicio del capitalismo extractivista, los pueblos indígenas andinos que han podido resistir a la geoculturización ${ }^{2}$

2 Wallerstein denomina geoculturización a la colonización de las perspectivas cognitivas, de los modos de producir u otorgar sentido a los resultados de la experiencia material o intersubjetiva, del imaginario, del universo de relaciones intersubjetivas del mundo, de la cultura en suma, a través de: 1) las expropiación a las poblaciones 
mantienen relaciones de correspondencia, complementariedad, relacionalidad y reciprocidad inexorable con los elementos naturales (Ávila 2016, 122-128). Estas conexiones vivenciales entre todos los elementos de la naturaleza con la cultura se conocen jurídicamente como "derechos bioculturales». Estos derechos puedes ser considerados como aquellos que conectan las comunidades, la tierra y sus ecosistemas a través de los derechos territoriales de propiedad tradicional (Bavikatte y Bennett 2015, 15).

A través de los derechos bioculturales se concilian los derechos de la naturaleza con los derechos de los pueblos y comunidades a gestionar su territorio de manera sostenible. Estos derechos deben ser leídos a la luz de dos enfoques complementarios: la interculturalidad y el ecocentrismo. Por un lado, la interculturalidad, de forma muy breve, podemos definirla como el reconocimiento radical de las diversas identidades, que poseen distintas relaciones intersubjetivas posibles, para construir discursos y diálogos democráticos con las voces de los excluidos. De esta forma, las políticas interculturales son entendidas como un proyecto político alternativo que guían las relaciones sociales (Fornet-Betancourt, 2002).

Por otro lado, el ecocentrismo es el conjunto de fundamentos éticos y políticos que justifican la protección de los ecosistemas a través de un modelo de sostenibilidad ecológica que permita el mantenimiento y regeneración de los ciclos naturales y la permanencia de las especies - humanas y no humanas - que habitan en un ecosistema. Ambos enfoques son fundamentales a la hora de comprender y gestionar los conflictos socio-ecológicos que se presentan en los territorios. De acuerdo a Morales-Betancourt y Estévez (2006, 39-51), con la colonización en América se introdujeron sistemas nuevos de apropiación de la tierra, desplazamiento de poblaciones a mayores altitudes e introducción de nuevas especies animales, como caballos y ganado vacuno y ovino, que ocasionaron una pérdida gradual de las formas tradicionales de subsistencia. Bajo este contexto cultural, los colectivos humanos que habitan en las cumbres montañosas de los páramos andinos y de los Himalayas indios han resistido al modelo extractivista colonial. Esto es visible en los diversos problemas de

colonizadas de los conocimientos que resultaban más aptos para el desarrollo del capitalismo. 2) La represión a las formas de producción de conocimiento de los colonizados, sus patrones de producción de sentidos, su universo simbólico, sus patrones de expresión y de objetivación de la subjetividad. 3) Imposición de la cultura de los dominadores en todo lo que fuera útil para la reproducción de la dominación (Quijano 2000, 209). 
contaminación en el Himalaya debido a que las actividades mineras, el turismo a gran escala y el tráfico de animales, obstaculiza el tránsito normal de las fuentes de agua hacia los suelos fértiles de los sistemas montañosos, lo cual impide que el ecosistema pueda ser correctamente protegido.

Con el fin de detener los procesos extractivistas, las comunidades campesinas e indígenas de Colombia, Ecuador y La India han recurrido al orden judicial para el reconocimiento y cumplimiento de tres derechos relacionados entre sí: los derechos de la naturaleza, los derechos culturales y los derechos de participación comunitaria. Los colectivos campesinos e indígenas mantienen un repositorio de conocimientos ecológicos respecto a las prácticas responsables de conservación de los páramos que ameritan ser tomados en cuenta por la jurisprudencia. Por ello, Fikret $(1999,6)$ afirma que los aspectos puramente ecológicos de la tradición no pueden separarse de lo social y lo espiritual. Las historias y leyendas son parte de la cultura y el conocimiento indígena porque implican significados y valores que están arraigados en la memoria colectiva del territorio. En los siguientes apartados se analizará la jurisprudencia colombiana, ecuatoriana e india referente a la protección de las altas montaña en relación con los derechos colectivos, lo cual nos permitirá entender el grado de perspectiva intercultural de las altas Cortes.

\section{El desarrollo de los derechos bioculturales, los derechos de participación y los derechos de la naturaleza en Colombia}

Colombia ha hecho considerables esfuerzos por dejar atrás un largo periodo de conflicto interno. Así, el problemático Acuerdo de paz y una justicia transicional incluye como uno de sus puntos centrales la resolución de los diversos conflictos socio-ecológicos violentos que se mantienen en el país, como la explotación minera en los páramos a cargo de grupos irregulares. Por lo tanto, el Estado debe detener la extrahección, que en términos de Gudynas (2013: 1), implica la extracción de recursos naturales con violencia; es decir, las consecuencias de una apropiación desmedida y arbitraria que pone en riesgo a la naturaleza y los derechos humanos de los habitantes de la zona. En este punto cabe señalar que el $2.5 \%$ de su superficie está compuesta por el sistema montañoso y cuenta con el 50\% del total de páramo andino. En este sentido, los páramos colombianos suministran el $70 \%$ de agua para el país y en ellos nacen varios ríos (Hofstede et al. 2014, 32). 
A fin de proteger los páramos, la Ley 1753 de 2015 prohíbe las actividades agropecuarias, de exploración o explotación de hidrocarburos y minerales en los páramos. La normativa colombiana debe ser leída a la luz de los estándares emitidos por la jurisprudencia colombiana, la misma que es producto de la constante movilización social de organizaciones amigas del páramo, como la iniciativa popular normativa en defensa del páramo el Almorzadero en Cerrito, Santander.

El proceso de consulta popular promovido por el movimiento en el municipio de Santander fue uno de los nueve que se realizaron sobre explotación en los páramos en toda Colombia desde el 2013 hasta el 20183. A través de las diversas técnicas de movilización políticojurídica (iniciativas de consultas populares, demandas judiciales y acciones demostrativas) los diversos grupos colombianos que habitan en los páramos reivindicaron varios derechos constitucionales ante la Corte Constitucional colombiana para proteger los páramos: Ios derechos bioculturales, los derechos de participación y los derechos de la naturaleza.

\subsection{Los derechos bioculturales como medio para vincular la cultura y la biodiversidad}

Recordemos que un «constitucionalismo interculturalizado» (Walsh $2009,28)$ reconoce la diversidad cultural, en la que se incluye las relaciones bioculturales distintas con la naturaleza, ya que para diversos pueblos y colectivos esta es vista como otro ser vivo. A través de la sentencia T-622, la Corte Constitucional reconoció los derechos bioculturales en Colombia, los cuales permiten preservar al mismo tiempo los ecosistemas y las prácticas tradicionales de las comunidades; un reconocimiento apropiado para gestionar los conflictos socioambientales que se producen en estos territorios.

Bajo el enfoque biocultural se deben evitar expropiaciones y desplazamientos forzosos de los colectivos que viven en territorios biodiversos, porque su partida implicaría el abandono de ecosistemas que pueden ser administrados sosteniblemente por las comunidades locales. De ahí que sean las propias comunidades quienes se resisten al funcionamiento de las actividades ilícitas como el tráfico de animales,

3 Entre estos municipios se encuentran los siguientes: Piedras, Tauramena, Cabrera, Cajamarca, Cumaral, Jesús María, Sucre, Pijao y Arbeláez (Semana Sostenible 2018). 
la minería ilegal o la deforestación, porque reconocen el valor que representa la naturaleza para el mantenimiento de todas las formas de vida. Por lo tanto, a fin de entender la naturaleza y la comunidad como dos entes que se auto protegen, Enrique Leff nos invita a pensar en el territorio como el vínculo que une a la naturaleza con el ser humano:

El territorio es el lugar donde la sustentabilidad se enraíza en bases ecológicas e identidades culturales. El territorio es el locus de las demandas y los reclamos de la gente para reconstruir sus mundos de vida. El nivel local es donde se forjan las identidades culturales, donde se expresan como una valorización social de los recursos económicos y como estrategias para la reapropiación de la naturaleza. El territorio es un espacio donde se precipitan tiempos diferenciados, donde se articulan identidades culturales y potencialidades ecológicas. Es pues el lugar de convergencia de los tiempos de la sustentabilidad: los procesos de restauración y productividad ecológica, de innovación y asimilación tecnológica, de reconstrucción de identidades culturales... Cada cultura define sus tiempos a través de sus cosmologías y sus sistemas simbólicos (Leff 2002, 206).

De esta forma, la Corte Constitucional, al momento que reconoce los derechos bioculturales, actúa bajo un enfoque pluralista e intercultural, que amplía la visión heterogénea del conflicto territorial y nos invita a pensar en la protección de la cultura y de la naturaleza de forma relacional e interdependiente.

\subsection{El derecho a la participación comunitaria como herramienta para proteger la naturaleza}

La interculturalidad propone un «equilibrio epistemológico» (Fornet-Betancourt 2006, 53) para la construcción de universalidades compartidas; por tal motivo, la participación comunitaria es fundamental para la construcción de una democracia intercultural y ecológica, ya que permite al Estado salir del monismo sociojurídico abstracto para acercarse al pluralismo real de las sociedades heterogéneas. La participación comunitaria puede ser definida como el desarrollo de procesos reflexivos y continuos fundados en la acumulación de experiencias y la democratización de conocimientos mediante los cuales las comunidades se organizan para el logro de mejores condiciones de vida (Mulet y Castanedo 2002). 
El principio democrático es uno de los principales enfoques de la teoría intercultural porque promueve el diálogo como forma de comprender el conflicto que es inherente a las sociedades que mantienen intereses diversos e incluso contrapuestos. De ahí que Mayorga $(2013,6)$ sostiene que la democracia intercultural es un proceso porque los vínculos entre las formas de democracia se ampliarán a medida que se vayan consolidando las nuevas entidades estatales, sobre todo los gobiernos departamentales y las autonomías indígenas. En la sentencia T-361/17 de 30 de mayo de 2017, la Corte Constitucional desarrolla el derecho de la participación comunitaria en temas ambientales, siguiendo parámetros dados por sentencias anteriores. De esta forma, la alta Corte estableció cuatro elementos que debe contener el derecho a la participación: Participación previa, intervención amplia de la comunidad, participación deliberada, consciente y responsable y participación efectiva y eficaz. Desde el enfoque intercultural que aborda la Corte Constitucional no basta con cumplir con un proceso de sociabilización como mero requisito formal, sino que se requiere un verdadero diálogo entre Estado-comunidades que termine en un consenso en un disenso justificado.

De igual manera, el desarrollo jurisprudencial del contenido del derecho de participación comunitaria se puede observar en la sentencia sobre la protección al páramo de Santurbán. Este páramo posee 24 ecosistemas naturales a lo largo de 30 municipios en los que existen grandes concesiones mineras como Greystar -Eco Oro- (Cañón y Mojica 2017, 110). En el año 2009, se concedió a la empresa peruanocanadiense una licencia ambiental para una explotación minera en el páramo de Santurbán, sin importar que el ecosistema paramuno provee recursos hídricos a las ciudades de Bucaramanga y Cúcuta, así como a las demás ciudades aledañas (Jiménez 2014, 1). Por lo tanto, las organizaciones de la sociedad civil, tras un largo litigio infructuoso, presentaron una acción de tutela ante la Corte Constitucional por la vulneración del derecho al acceso a la información y a la participación comunitaria ambiental de los habitantes paramunos. La alta Corte afirmó en la sentencia (T-361/17) el derecho a la participación ambiental desde la perspectiva de la gobernanza en los territorios paramunos que necesitan de una protección especial por ser un ecosistema con amplia diversidad y regulador del ciclo hídrico (Sentencia T-361/17, 30 de mayo de 2017).

En este litigio, la Corte Constitucional estableció que el Ministerio del Ambiente vulneró el derecho de participación, ya que no se suministró el proyecto de la Resolución 2090 de 2014 para que los accionantes conocieran la medida provisional de la administración. 
Además, no se realizó una convocatoria amplia y abierta que incluyera a todos los afectados con la delimitación de ese bioma; y, finalmente, no se construyeron espacios de diálogo y deliberación que permitieran a la colectividad intervenir de manera efectiva y significativa en la delimitación y regulación de ese nicho ecológico. Se trata, entonces, de un caso en el que la alta Corte reprocha la indebida actuación de la administración colombiana, la cual renunció a buscar el consentimiento libre de la ciudadanía, a través de un consenso razonado, y se limitó a acudir a las mesas de concertación con una decisión de delimitación ya tomada. (Sentencia T-361/17, 30 de mayo de 2017).

Siguiendo la misma línea, la consulta popular es otro mecanismo al que han recurrido las comunidades para efectivizar el derecho a la participación. En el año 2018, la Corte Constitucional de Colombia estableció que la consulta popular no es procedente e idónea para ejercer la participación ciudadana y dar aplicación a los principios de coordinación y concurrencia entre nación y territorio (Sentencia SU095/18, 11 de octubre de 2018), lo cual contradice su propia línea jurisprudencial. Por lo tanto, se colige que la Corte Constitucional colombiana desarrolla el derecho a la participación a través de la consulta previa, pero restringe este mismo derecho cuando se trata de una consulta popular. Lo que ocurre es que en Colombia, al igual que en Ecuador, los resultados de la consulta previa — de acuerdo a la norma vigente- no tienen efecto vinculante, lo que implica que la última palabra sobre la autorización de un proyecto extractivista no la tiene la ciudadanía sino el parataje estatal. Por el contrario, en lo referente a la consulta popular, la jurisprudencia colombiana, en sus primeras sentencias afirmó la obligatoriedad de los resultados de la consulta popular, pero al darse cuenta del apoyo ciudadano a la prohibición de la extracción minera, optaron por aplicar un virement de la línea jurisprudencial para afirmar que las consultas populares locales no son aplicables para temas extractivistas que son de interés nacional.

\subsection{El reconocimiento de los páramos y sus fuentes de agua como sujetos de derechos}

Los fundamentos del ecocentrismo nos invitan a pensar en la importancia de proteger y mantener los ciclos vitales de la naturaleza con el fin de evitar un daño ecológico que puede ser irreversible si no existen políticas de conservación y restauración. Las decisiones públicas deben ser construidas con base a la participación entre el Estado y las comunidades involucradas en la conservación de los páramos para 
evitar una afectación a las relaciones ecocéntricas entre la cultura paramuna y la naturaleza. Siguiendo esta línea, la Corte Constitucional colombiana, en la sentencia T-622 ratifica que la Constitución es ecológica. ${ }^{4}$

Debido a la presencia de megaproyectos mineros en Colombia, son varios los procesos judiciales que se han iniciado por parte de las comunidades campesinas en contra del extractivismo. Esto se da en razón de que la actividad minera interfiere en el recurso hídrico de la población, porque los páramos son el ecosistema donde se genera el agua destinada al consumo humano y al riego. Por tal motivo, la Corte Constitucional colombiana ha entendido la relación directa que se da entre la protección del páramo y el derecho fundamental al agua, así los sostuvo en la sentencia C-016 de $2016^{5}$.

Consecuentemente, los páramos son valorados por la alta Corte debido a que son proveedores del recurso hídrico que es indispensable para las diversas actividades humanas: agua potable para consumo personal, agua de riego, abrevadero de animales, etc. De igual modo, en la sentencia C-035 de 2016, la Corte Constitucional señaló que, ante la vulnerabilidad, fragilidad y dificultad de recuperación de los ecosistemas de páramo, el Estado tiene a su cargo la obligación de brindar una protección más amplia y especial, dirigida específicamente a preservar este tipo de ecosistema. Esta afirmación responde a que el páramo es un tipo de bioma que no es común en el mundo, que presta una serie de servicios ecológicos como la provisión de agua a las comunidades.

Siguiendo la misma línea, la sentencia T-622 reconoció que los ríos - en su calidad de fuente de agua - son una entidad con derecho a la protección, conservación, mantenimiento y restauración a cargo del Estado y las comunidades étnicas. Precisamente, a fin de proteger la cuenca del río Atrato, en donde se encuentran el Páramo de Urrao y el Páramo Frontino-Urrao, la Corte Constitucional señaló lo siguiente:

El derecho fundamental al agua se hace efectivo mediante el cumplimiento de las obligaciones del Estado de garantizar la protección y subsistencia de las fuentes hídricas, así como la disponibilidad, accesibilidad y calidad del recurso... el derecho al agua tiene una doble dimensión en tanto derecho fundamental como servicio público esencial. En particular, esto es de especial relevancia

4 Colombia, Corte Constitucional, Acción de tutela, T-622 de 10 de noviembre de 2016

5 Colombia, Corte Constitucional, sentencia C-016-16, 27 de enero de 2016, párrafo 169. 
para los grupos étnicos en la medida en que la preservación de las fuentes de agua y el abastecimiento de la misma en condiciones dignas es esencial para la supervivencia de las culturas indígenas y tribales, desde una perspectiva biocultural (Corte Constitucional de Colombia, 10 de noviembre de 2016).

Así, la preservación de las fuentes de agua cobra especial relevancia cuando se trata de un litigio que versa sobre territorios pertenecientes a colectivos y comunidades que mantienen estrechas relaciones con la naturaleza. Así lo señalan Izquierdo y Viaene $(2018,5)$ cuando analizan la relación entre los pueblos indígenas y la naturaleza: "Según los indígenas, claro que sí, el territorio habla y expresa sus sentimientos. Una montaña se enoja, se pone triste, y lo expresa a través de señales en los sueños de los ancianos, ceremonias de fuego o porque ocurren accidentes con la gente».

En agosto de 2018, el Tribunal Administrativo de Boyacá declaró como sujeto de derechos al páramo de Pisba, donde habitan aproximadamente 6.500 personas que viven de la agricultura, la ganadería y la minería artesanal (Olmos 2018). La sentencia del Páramo de Pisba nos recuerda que los páramos son entidades de especial importancia por una doble función jurisprudencialmente reconocida: la producción de agua y la absorción de carbono de la atmósfera.

Cabe señalar que la delimitación de los páramos como territorios vedados al extractivismo ha contribuido a restringir la extracción minera; sin embargo, existe la dicotomía respecto a la importancia que la minería representa para ciertos miembros de las comunidades de la zona de Pisba que laboran para las empresas mineras. De ahí que varios pobladores no estén de acuerdo con la suspensión de las actividades de extracción de minerales. Por lo tanto, a fin de no vulnerar el derecho al trabajo de las comunidades, el Tribunal Administrativo de Boyacá recordó que las personas afectadas por las medidas de prohibición minera deben ser compensadas o reubicadas laboralmente. (Expediente: 152383333002201800016 01, 9 de agosto de 2018). Esta disposición implica una materialización de la justicia ecológica puesto que no basta con limitar o restringir el extractivismo, sino que al mismo tiempo se requiere ofrecer a las comunidades — que de manera tradicional se han dedicado a esta actividad a la que denominan baqueteo - otras fuentes de empleo que sean sostenibles.

No cabe duda de que la epistemología andina, construida desde las comunidades y colectivos de los páramos colombianos, debe ser considerada en las decisiones de las Cortes, especialmente en un contexto de justicia posconflicto, que bien puede convertirse en un 
referente de justicia transicional intercultural, tal como lo señalan Izquierdo y Viaene $(2018,5)$ :

Colombia puede convertirse en un laboratorio donde los pueblos indígenas trasciendan los límites y las prácticas del paradigma dominante de la justicia transicional. Sin embargo, el gran desafío que enfrenta el proceso de justicia transicional colombiano es cómo abordar y poner en práctica estas múltiples visiones de daño, justicia, reparación y reconciliación, enclavadas en ontologías indígenas.

En este sentido, el orden judicial debe realizar una lectura histórica que le permita comprender la realidad de las comunidades, la cual sigue siendo de violencia y de despojo.

\section{La protección de los páramos en Ecuador a través de los derechos de la naturaleza y los derechos de participación}

El territorio de Ecuador contiene $14.876 \mathrm{~km}^{2}$ de páramo; el cual cubre el 5,94\% del territorio nacional (Ministerio del Ambiente de Ecuador 2012, 131). Esto lo convierte en el país de la región con más porcentaje de páramo, superando proporcionalmente a Colombia. Además, el propio Ministerio de Ambiente de Ecuador ha identificado 12 ecosistemas de páramos. Esta variedad responde a las distintas condiciones climáticas que tienen los páramos, que van desde los secos en el Chimborazo, hasta los húmedos (Hofstede et al. 2014, 21).

El grado de protección que tienen los páramos en Ecuador se encuentra consagrado en la Carta Magna en dos derechos constitucionales: los derechos de la naturaleza y los derechos de participación. En este punto, cabe recordar que, de acuerdo a la Constitución ecuatoriana, los derechos son de directa e inmediata aplicación por parte de cualquier servidor público. De ahí que es deber de las Cortes tutelar cabalmente estos derechos; labor que, como veremos a continuación, todavía se encuentra pendiente.

\subsection{El limitado avance de los derechos de la naturaleza en Ecuador}

La Constitución ecuatoriana en su art. 71 reconoce que la naturaleza o Pacha Mama, donde se reproduce y realiza la vida, tiene derecho a que se respete integralmente su existencia y el mantenimiento y regeneración de sus ciclos vitales, estructura, 
funciones y procesos evolutivos. Esta disposición constitucional es una herramienta para que las comunidades paramunas, que en su mayoría son indígenas, puedan defender sus territorios biodiversos amenazados por los procesos extractivistas y contaminantes. Hay que recordar que este artículo debe interpretarse a la luz de los derechos colectivos de las comunas, comunidades, pueblos y nacionalidades indígenas, tales como el derecho a conservar la propiedad imprescriptible de sus tierras comunitarias, mantener la posesión de las tierras y territorios ancestrales y obtener su adjudicación gratuita y participar en el uso, usufructo, administración y conservación de los recursos naturales renovables que se hallen en sus tierras (art. 57).

En noviembre de 2012, la Corte Nacional de Justicia del Ecuador ya tuvo oportunidad de pronunciarse respecto a un litigio que versó sobre la protección de la población que habita en el Cerro Achupallas que se encuentra en el lindero con el Parque Nacional Podocarpus (ubicado en las provincias de Loja y Zamora Chinchipe). En este caso, la comunidad demandó a una operadora telefónica (CLARO) por la construcción, instalación y operación de una antena de enlace telefónico celular aduciendo que las antenas de telefonía móvil tienen efectos nocivos y dañinos significativos en la salud humana y en el entorno natural. La Corte reconoció que el Parque Podocarpus es un área con criterio de conservación a nivel del planeta, por lo que amerita protección y estableció la importancia de garantizar el ejercicio del art. 71 de la Constitución, que reconoce los derechos de la naturaleza, y del art. 397, que establece la inversión de la carga de la prueba sobre la inexistencia de daño potencial o real que genera una actividad contaminante. Por lo tanto, la Corte estableció una reparación debido a los daños ocasionados a la salud y a los ecosistemas (Corte Nacional de Justicia, Juicio n. ${ }^{\circ}$ 117-2010, 9 de noviembre de 2012).

Como vemos, el hecho de que exista un reconocimiento constitucional facilita la labor interpretativa de los jueces, quienes pueden sustentarse en este derecho para otorgar protección tanto a la biodiversidad como a las comunidades que habitan en los páramos, principalmente en aquellas zonas consideradas como «áreas protegidas». Siguiendo la misma línea, cabe señalar que la ley ecuatoriana otorga a la Corte Constitucional la facultad de seleccionar sentencias que tratan temas relevantes a fin de emitir criterios que constituyan jurisprudencia obligatoria (LOGJCC, art. 25). Así, la alta Corte seleccionó dos casos que versan sobre la protección a territorios biodiversos que se ubican en la serranía ecuatoriana.

El primer caso versa sobre sobre el litigio protagonizado por la comunidad campesina de San Pablo de Amalí (Provincia de Bolívar) 
en contra de la hidroeléctrica Hidrotambo, que habría violentado los derechos humanos de la comunidad y los derechos de la naturaleza debido al desbordamiento del río y otros conflictos. El 6 de mayo de 2019, la Corte Constitucional seleccionó este caso a fin de desarrollar los estándares y límites respecto de la explotación de recursos renovables y no renovables que son gestionados por el Estado, la actuación de las empresas concesionarias, y su impacto en el goce y ejercicio de los derechos colectivos y de la naturaleza. Hasta el momento la Corte no ha emitido una decisión sobre este caso (Caso n. ${ }^{\circ}$ 502-19-JP).

El segundo caso seleccionado por la Corte Constitucional se relaciona con la violación de los derechos de la naturaleza debido a una autorización ambiental otorgada por el Ministerio del Ambiente y Agua para que se realicen actividades mineras dentro del Bosque Protector "Los Cedros» - Provincia de Imbabura-. Este caso fue elegido el 18 de mayo de 2020, ya que la Corte consideró necesario analizar las afectaciones a los derechos de la naturaleza y, particularmente, a la biodiversidad que habita en el bosque, como las últimas poblaciones del mono araña en estado crítico de conservación, y del oso andino (oso de anteojos) en peligro de extinción. Hasta el momento, la Corte aún no se ha pronunciado y se espera que esta sentencia desarrolle el contenido de los derechos de la naturaleza, en lo referente a áreas declaradas como bosques protectores (Caso n. $\left.{ }^{\circ} 1149-19-J P\right)$.

Cabe señalar que las poblaciones andinas mantienen estrechas relaciones con la naturaleza, principalmente con el agua, los animales, la tierra, porque gracias a estos pueden desarrollar sus actividades tradicionales. Por ejemplo, los indígenas de la serranía valoran el agua desde diversas perspectivas (como deidad y objeto de culto, como elemento de su cosmovisión, como base de sus sistemas productivos y como elemento terapéutico y de sanación). Ese es el caso de los habitantes de la comunidad Fakcha Llakta6, ubicados en la provincia de Imbabura, para quienes el agua se configura como un ser vivo que da vida y garantiza el Sumak Kawsay: «Dentro del agua se están formando seres vivos y es por eso que, en este mundo, no podemos vivir sin agua. (...) El agua es la principal vida del cuerpo humano» (Trujillo et al. 2018, 2-10). Para la cultura andina el agua representa un símbolo sagrado "porque es el seno de nuestra madre tierra, de mi mamá, de Pachamama, que es ¡mi mamá!», que amerita reciprocidad: «me das

6 La comunidad se encuentra ubicada en la localidad de Peguche, Parroquia Dr. Miguel Egas Cabezas, Cantón Otavalo-Ecuador. 
vida y energía y, yo también tengo que cuidarte». Al mismo tiempo, el agua implica el medio para alcanzar el bienestar humano: "Gracias a este sitio sagrado tenemos agua para comer, agua para tomar y agua para piscina, jestamos feliz! (Trujillo et al. 2018, 2-10).»

Los distintos mitos indígenas nos demuestran que los pueblos indígenas mantienen historias comunes con los animales, ríos y montañas, pues comparten el fondo común ontológico: la vida en su sentido profundamente humano (sujeto) en la que se incluyen a los nohumanos (Castro de Viveiros 2013, 17). De ahí que sea necesario que la Corte Constitucional, al momento de resolver conflictos ambientales en contextos interculturales, tome en consideración que los vínculos que existen entre comunidades y terriorios biodiversos son distintos a los que tienen los citadinos en sus entornos naturales. Para una comunidad que vive bajo el principio del bioculturalismo, perder un bosque, un caudal ecológico o una especie significa el despojo de su propia cultura; es decir, de su existencia.

\subsection{La protección a los páramos a través de la aplicación de los derechos de participación}

El derecho a la participación comunitaria ha sido discutido en las altas Cortes sin que hasta el momento se tenga una sentencia que concretice plenamente el ejercicio del principio democrático. El reconocimiento de los derechos de participación se encuentra directamente relacionado con la vida democrática del Estado intercultural y plurinacional de derechos presente en la Constitución de Ecuador. En la doctrina, la democracia comunitaria es sinónimo de la democracia intercultural, categoría que fue promovida por el movimiento indígena con los distintos levantamientos en la década del noventa del siglo xx; sin embargo, tal como señala Rodríguez (2017, 115), el desarrollo de los derechos culturales se realizó en el contexto económico neoliberal.

En el art. 104 de la Carta Magna se establece que la ciudadanía podrá solicitar la convocatoria a consulta popular sobre cualquier asunto nacional siempre que cuente con el respaldo de un número no inferior al 5\% de las personas inscritas en el registro electoral; y sobre un asunto de carácter local si tiene el respaldo de al menos el $10 \%$ del correspondiente registro electoral. Hay que resaltar que el art. 57 de la norma suprema establece el derecho de las comunidades, pueblos y nacionalidades indígenas a la consulta previa, libre e informada, dentro de un plazo razonable, sobre planes y programas de 
prospección, explotación y comercialización de recursos no renovables que se encuentren en sus tierras y que puedan afectarles ambiental o culturalmente. Sin embargo, el Estado ecuatoriano ha autorizado mega proyectos mineros y petroleros en territorios en los cuales habitan campesinos que son expropiados de sus tierras y de su cultura a través de procesos de extrahección.

De hecho, la Constitución de Ecuador establece (art. 398) que toda decisión o autorización estatal que pueda afectar al ambiente deberá ser consultada a la comunidad, a la cual se informará amplia y oportunamente. Así, se extiende el derecho a la consulta en temas ambientales, no solo a favor de los colectivos indígenas, sino en beneficio de todas las personas que vean en riesgo sus derechos a causa del extractivismo; por ejemplo, los campesinos. Cabe señalar que, en la práctica, la consulta previa no se cumple. De hecho, las medidas de reparaciones que dictó la Corte Interamericana de Derechos Humanos en el caso Sarayaku vs. Ecuador (2012), son uno de los casos emblemáticos de la región Latinoamericana en cuanto al incumplimiento estatal de efectuar la consulta previa.

Frente a las limitaciones de la consulta previa, una de las estrategias de resistencia de los colectivos en defensa de sus territorios biodiversos ha sido justamente ampliar las estrategias de lucha antiextractivista hacia otras instituciones jurídicas como la consulta popular. De hecho, varias parroquias rurales del país se han organizado para proteger a los páramos, así como la gestión del agua, recurriendo para ello a la consulta popular, que de acuerdo a la Constitución es de cumplimiento obligatorio (art. 106). Uno de los casos más conocidos es la consulta popular realizada sobre la aprobación o rechazo a la explotación minera en el páramo de Kimsakocha del cantón Cuenca, y dos de sus parroquias rurales, Victoria del Portete y Tarqui. Sus pobladores paramunos, hasta antes del proceso de consulta efectuado en el año 2018, llevaban alrededor de 15 años de resistencia minera en los páramos contra el proyecto Minero Loma Larga-Kimsakocha que se pretendía ejecutar dentro del ecosistema en el que se encuentran cerca de 35 sistemas de aguas destinadas a las comunidades y ciudades cercanas (Zhagui y Ruiz 2018, 306).

La consulta de Kimsakocha fue promovida por los habitantes paramunos y el movimiento indígena ecuatoriano, ya que desde la concesión minera no se había realizado un proceso sistemático de consulta previa a los pueblos indígenas que habitan en la zona, ni ningún tipo de participación en la delimitación del páramo. Tras un largo proceso administrativo y judicial que inició en el año 2012, finalmente el 24 de marzo de 2019 se pudo efectuar la Consulta 
Popular a los habitantes del cantón Girón de la provincia del Azuay. Los resultados arrojaron que el $86,7 \%$ de los votantes estaban en contra de que se realicen actividades mineras en los páramos o fuentes de agua del sistema hidrológico. Sin embargo, la voluntad popular no fue respetada y actualmente se encuentra en ejecución el proyecto Minero Loma Larga-Kimsakocha. En el mismo año, el prefecto indígena de la provincia del Azuay, Carlos Pérez Guartambel promovió otra consulta popular local sobre la protección de los páramos en la que se pretendía preguntar a los habitantes del Azuay:

¿Está usted de acuerdo con la prohibición, sin excepción, de actividades de prospección, exploración y explotación de minería metálica en fuentes de agua, zonas de recarga, descarga y regulación hídrica, páramos, humedales, bosques protectores y ecosistemas frágiles en la provincia del Azuay? (Corte Constitucional, 17 de septiembre de 2019).

Dicha consulta no llegó a ejecutarse puesto que la Corte Constitucional aduciendo que la pregunta no había superado el control constitucional del cuestionario. Sin embargo, la alta Corte, en su dictamen desfavorable señaló que las Consultas populares sobre explotación de recursos naturales y proyectos extractivistas tienen carácter constitucional y cumplen con el principio democrático establecido en la Carta Magna (Dictamen n. ${ }^{\circ}$ 19-19CP/19, 17 de septiembre de 2019).

Por otro lado, en cuanto a la competencia del Estado sobre los recursos del subsuelo, la Corte constitucional ecuatoriana fue clara en señalar que no existe una incompatibilidad entre la competencia del Estado y los derechos de participación. A pesar de que la Constitución ecuatoriana reconoce los derechos de la naturaleza en general y la protección de los páramos en particular, no queda claro el tipo de protección y conservación que estos deben tener. El Código Orgánico del Ambiente (art. 5) también establece que la población tiene derecho a vivir en un ambiente sano, lo que incluye el manejo sostenible de los ecosistemas, con especial atención a los ecosistemas frágiles y amenazados tales como páramos, humedales, bosques nublados, bosques tropicales secos y húmedos, manglares y ecosistemas marinos y marinos-costeros. Además, esta norma declara que los páramos son áreas protegidas y no pueden ser objeto de ningún tipo de actividad extractiva, tal como lo señala el art. 407 de la Constitución. No obstante, la ley le otorga la competencia exclusiva a la Autoridad Ambiental Nacional —Ministerio del Ambiente_ para considerar los criterios de áreas protegidas. Una contradicción de las competencias 
del Estado que dejan un vacío en cuanto a la protección de los páramos y la participación de la población paramuna.

Ecuador perdió un momento ideal para construir una justicia intercultural que permita la construcción de un dialogo horizontal con los colectivos humanos excluidos de las decisiones públicas, quienes llevan sobre sus hombros una historia de resistencia al capitalismo colonial. Una decisión que, además, contradice con lo establecido en el preámbulo de la Constitución ecuatoriana cuando señala que el pueblo soberano de Ecuador es heredero de las luchas sociales de liberación frente a todas las formas de dominación y colonialismo.

\section{La protección de los Himalayas de la India a través de los derechos de la naturaleza}

A pesar de las diferencias culturales y la distancia geográfica que separan a las montañas andinas y a los Himalayas indios, las altas Cortes de Colombia, Ecuador y La India han apostado por resolver litigios sobre conflictos socio-ecológicos bajo un nuevo fundamento derivado del reconocimiento de los derechos de la naturaleza. Las altas Cortes de La India han mostrado un evidente interés en la protección de la diversidad cultural y religiosa al momento de resolver los litigios que versan sobre proyectos extractivistas y contaminación a la naturaleza. En La India se estima que los flujos de ríos vitales para los cultivos de los agricultores, que dependen del agua de deshielo de los glaciares en la estación seca, son interrumpidos debido al derretimiento de un tercio del hielo en el Himalaya y el Hindú Kush (Gopal 2019, 1).

Por otro lado, las especies silvestres que habitan en los macizos indios también se están viendo afectadas. De acuerdo con la UNESCO $(2005,138)$, los cerros boscosos de las faldas del Himalaya acogen a numerosas especies animales en peligro de extinción cuya principal amenaza es la caza ilegal, principalmente de rinocerontes. Adicionalmente, no solo las actividades extractivas de minerales como la bauxita están contaminando los Himalayas, sino también la deforestación y el turismo religioso a gran escala. En países sumamente creyentes como la India7, el exceso de visitas turísticas a lugares

7 High Court of Uttarakhand at Nainital, 20 de marzo de 2017: Los hindúes tienen una profunda conexión espiritual con el Ganges y el Yamuna. Según las creencias hindúes, un baño en el río Ganges puede lavar todos los pecados. El Ganges también se llama 'Ganga Maa'. Se encuentra mencionado en las antiguas escrituras hindúes, incluyendo Rigveda. 
sagrados que se encuentran dentro de los ecosistemas frágiles acelera el deterioro del sistema de los Himalayas, debido a la falta de conciencia ambiental que provoca extracción de especies de su hábitat natural, contaminación del suelo y cuerpos de agua debido al mal manejo de residuos, etc. (Pérez et al. 2009, 5).

La alta Corte de Uttarakhand at Nainital señaló a dos glaciares que están siendo afectados: el glaciar Gangotri —situado en el Estado de Uttarakhand-, que sufre un derretimiento sistemático desde 1971. El glaciar es la fuente de la que nace el río Ganges - considerado una deidad en la India-. Por otra parte, el glaciar Yamunotri localizado en el Estado de Uttarakhand — de donde nace el río Yamuna - también está retrocediendo a un ritmo alarmante (High court of Uttarakhand at nainital, 30 de marzo de 2017). Por tal motivo, la Corte, con fundamentos científicos, jurídicos y filosóficos, decidió otorgar derechos, deberes y responsabilidades a favor de la naturaleza, específicamente de los glaciares Yamunotri y Gangotri, así como a ríos, arroyos, riachuelos, lagos, aire, prados, valles, selvas, bosques, humedales, praderas, manantiales y cascadas (High court of Uttarakhand at Nainital, 30 de marzo de 2017). La sentencia que dispone proteger a los glaciares es mucho más holística que la conocida sentencia a favor de los ríos Ganges y Yamuna (High court of Uttarakhand at Nainital, 20 de marzo de 2017), puesto que no se basa únicamente en la religión para justificar la necesidad de otorgar derechos a varios elementos de la naturaleza, sino que además evidencia la crítica situación de los glaciares y los efectos negativos de su degradación para el cambio climático.

En cuanto al argumento biológico, la alta Corte señala que el hielo glaciar es el mayor reservorio de agua dulce en la tierra, y que en el Estado de Uttarakhand hay varios parques naturales que están siendo amenazados por factores antrópicos, entre ellos, la deforestación a gran escala que está despojando a la montaña de bosques y selva. Adicionalmente, el orden judicial nos recuerda que estos parques naturales funcionan como pulmones para toda la atmósfera (High court of Uttarakhand at Nainital, 30 de marzo de 2017). Por lo tanto, La India, al igual que Ecuador y Colombia, reconoce la importancia de proteger los ecosistemas biodiversos. Recordemos que, por un lado, el orden judicial colombiano estableció la importancia de preservar los páramos de Pisba y Santurbán por ser fuentes vitales de agua para el ser humano y para las miles de especies que habitan en los páramos. Por otro lado, las altas Cortes de Ecuador -tanto la Corte Constitucional como la Corte Nacional de Justicia- afirmaron la importancia de que el orden judicial emita parámetros que permitan 
preservar las áreas protegidas que son el hábitat de cientos de especies. En lo referente a los fundamentos filosóficos, la Corte de Uttarakhand, desde una hermenéutica intercultural, señala que las escrituras religiosas profesan la necesidad de proteger a los elementos de la tierra garantizándoles el pleno goce del derecho a un hábitat saludable. También se cita la relación que existe entre los árboles y la religión, y la importancia de estos para el mantenimiento de la cultura, para lo cual cita a la ecologista keniana premio nobel de la paz, Wangari Muta Maathai (High court of Uttarakhand at Nainital, 30 de marzo de 2017).

Además, la Corte cita normas internacionales y de derecho comparado que justifican la necesidad de proteger a los ríos y bosques ${ }^{8}$. Finalmente, la sentencia hace referencia - tal como lo hizo la sentencia colombiana T-622 de 2016 sobre el río Atrato- a la ley neozelandesa Te Awa Tupua Act 2014, que declaró al Parque Nacional de Te Urewera como persona jurídica con el fin de preservar el parque, los sistemas ecológicos indígenas, la biodiversidad y su patrimonio cultural histórico. Se designó a los representantes (personas in loco parentis) para proteger, conservar y preservar los ecosistemas del Estado de Uttarakhand y se aclaró que los derechos de estas personas jurídicas son equivalentes a los derechos de los seres humanos, y los daños causados a estos organismos se tratarán como lesiones causadas a los seres humanos. Un reconocimiento que retoma los valores propios de la cultura hindú con lo más avanzado sobre protección a la naturaleza. Se trata de un ejercicio hermenéutico que no solo es intercultural al interior de su propia diversidad, sino también exterior, pues dialoga con otros ordenamientos jurídicos (Nueva Zelanda) que reconocen la importancia de abordar estos litigios desde la bioculturalidad.

En la sentencia de los glaciares se desarrolla los fundamentos éticos que permiten comprender la relación entre la cultura de los ciudadanos indios y sus afecciones por la naturaleza. La Corte dispone al Estado Indio que tome las medidas necesarias para regularizar los 50 crematorios que se encuentran funcionando ilegalmente, y que se vigile que todas las industrias, hoteles, monasterios y otros establecimientos que descarguen sus aguas servidas a los ríos sean clausurados. Claro está que el reconocimiento jurisprudencial de las fuentes de agua como sujetos de derechos no basta para garantizar su protección, por lo que se requiere la voluntad política de los diferentes órganos

8 La Convención sobre el comercio internacional de especies amenazadas de fauna y flora silvestres, La Declaración de Tilari de 30 de mayo de 1968, La Conferencia de las Naciones Unidas sobre Medio Ambiente (High court of Uttarakhand at Nainital, 30 de marzo de 2017). 
estatales a fin de que ejecuten a cabalidad las órdenes judiciales. En la práctica, a pesar de que los glaciares Yamunotri y Gangotri son considerados sujetos con derechos, actualmente el gobierno de la India está ejecutando un proyecto para la construcción de la carretera Char Dham de una longitud de $900 \mathrm{~km}$ en una zona ecológicamente sensible de Uttarakhand, que conecta los cuatro principales sitios de peregrinación hindú: Yamunotri, Gangotri, Kedarnath y Badrinath.

El gobierno justifica la pertinencia de esta obra con el argumento de que la carretera facilitará el tránsito de peregrinos al Char Dham y el despliegue militar para la defensa de la frontera con China. Sin embargo, los grupos ecologistas han realizado una serie de protestas en contra de este proyecto, denunciando que la construcción de una carretera de esas magnitudes en la zona montañosa de Uttarakhand estaría convirtiendo al sitio en una zona de deslizamiento activo. Los impactos de los grandes proyectos y obras públicas ya fueron visibilizados durante las inundaciones de 2013 que se cobraron casi 6.000 vidas e infligieron daños por miles de rupias.

Las políticas públicas de desarrollo económico —basadas en el turismo religioso y la defensa del Estado- han dado carta abierta a la construcción de una mega obra que está causando serios impactos ecológicos en las montañas indias. Esto es contrario al orden judicial que ha puesto en evidencia la necesidad de garantizar la protección de bosques y ríos por su valor ético, biológico y social. La apuesta por el desarrollo económico sobre la preservación de la naturaleza termina avalando la contaminación de las fuentes de agua y de la biodiversidad presente en una zona determinada.

\section{Conclusiones}

La explotación a la naturaleza ha sido posible debido a la consolidación del pensamiento logocéntrico que representa un proyecto monocultural para ordenar el mundo en función de la modernidad. Además, crea un contexto cada vez más economizado, tecnificado y destructivo con el ambiente (Escobar 2012, 148). Esta investigación evidencia el hito jurídico-político que marcaron las altas Cortes de Colombia y La India al otorgar el estatus de sujeto de derechos a los páramos y a los glaciares.

De igual modo, se ha puesto en evidencia que las altas Cortes ecuatorianas, a pesar de tener un marco constitucional favorable a la naturaleza, aún no logran desarrollar el contenido de estos derechos. Estos tribunales tampoco han efectivizado el derecho a la consulta 
previa y a la consulta popular, a pesar de ser dos mecanismos idóneos para proteger la vida paramuna. De ahí que es necesario que la Corte Constitucional de Ecuador en sus futuros fallos, desarrolle los parámetros de protección hacia los páramos andinos. Estos parámetros se deben construir tomando en consideración tanto el principio de interculturalidad como el principio ecocéntrico plasmado a lo largo de la Carta Magna.

El análisis de las sentencias nos permite comprender que los derechos de la naturaleza, los derechos de participación y los derechos culturales deben ser interpretados simultáneamente a la luz de los principios de interculturalidad y ecocentrismo. Esto, debido a que la interculturalidad establece profundos diálogos frente a los conflictos ecológicos que se presentan en sociedades heterogéneas con éticas ecológicas distintas. La justicia no está exenta de estos diálogos, ya que debe promover una mayor comprensión de los fundamentos éticos sobre protección de los territorios biodiversos: los saberes de los colectivos que ven en el páramo su fuente de vida pasada, presente y futura deben ser respetados y protegidos, porque en ellos existe un fundamento ético legítimo. De igual modo, el ecocentrismo nos invita a deconstruir la idea generalizada respecto a que la naturaleza es un objeto apropiable que puede ser usado hasta su exterminio. Solo en la medida que los jueces garanticen el respeto a los principios de correspondencia, complementariedad y reciprocidad, que existe entre humanos y naturaleza, se podrá desarrollar el contenido de los derechos de la naturaleza bajo un enfoque intercultural y ecocéntrico.

La tarea pendiente de las altas Cortes está en alejarse de las normas que promueven la mercantilización de la vida y acercarse a los colectivos históricamente excluidos para construir un constitucionalismo intercultural y popular (Niembro 2013, 191-224); un constitucionalismo del oprimido (Ávila 2019); en definitiva, un constitucionalismo de la naturaleza que promueva una auténtica democracia de la tierra.

\section{Bibliografía}

Ávila, Ramiro. 2019. La utopía del oprimido, los derechos de la naturaleza y el buen vivir en el pensamiento crítico, el derecho y la literatura. México D.F.: Akal.

Ávila, Ramiro. 2016. El neoconstitucionalismo andino. Quito: Huaponi.

Bavikatte Kabir S. y Tom Bennett. 2015. «Community stewardship: the foundation of biocultural rights». Journal of human rights and the environment 1: 7-29.

Cañón Dora y Mojica Yuly. 2017. «El oro o el agua, el caso del páramo de Santurbán», Questionar: Investigación Específica 5, n. 11: 105-119. 
Castro de Viveiros, Eduardo. 2013. La mirada del jaguar: Introducción al perspectivismo amerindio. Buenos Aires: Tinta limón.

Echeverría, Bolívar. 2009. «¿Qué es la modernidad?», Cuadernos del seminario Modernidad: Versiones y Dimensiones. México, D.F.: UNAM.

Escobar, Arturo. 2012. Más allá del tercer mundo, globalización y diferencia. Bogota: Instituto colombiano de antropología e historia.

Fikret, Berkes. 1999. Sacred Ecology: Traditional ecological knowledge and resource management. Philadelphia: Taylor \& Francis.

Fornet-Betancourt, Raúl. 2006. La interculturalidad a prueba. Michigan: Mainz.

Fornet-Betancourt, Raúl. 2002. "Lo intercultural: el problema de su definición», Pasos 103: 1-3.

Gangaaction.org. 2020. «Ganga in Scriptures». Acceso el 1 de enero de 2020. https://www.gangaaction.org/about-ganga/national-heritage/ganga-inscriptures/

Gopal, Sharma, 2019. "Derretimiento de Himalaya afectará ríos y cultivos en Asia: estudio» Reuters, 4 de febrero. Acceso el 20 de marzo de 2020. https://Ita.reuters.com/articulo/clima-himalayas-idLTAKCN1PT1HI

Gudynas, Eduardo. 2013. "Extracciones, extractivismos y extrahecciones. Un marco conceptual sobre la apropiación de recursos naturales», Observatorio del Desarrollo 18.

Hofstede, Robert, Juan Calles, Víctor López, Rocío Polanco, Fidel Torres, Janett Ulloa, Adriana Vásquez y Marcos Cerra. 2014. "Los páramos andinos. ¿Qué sabemos? Estado de conocimiento sobre el impacto del cambio climático en el ecosistema páramo», UICN 156: 1-79.

Izquierdo, Belkis y Lieselotte Viaene. 2018. «Descolonizar la justicia transicional desde los territorios indígenas». Peace in Progress 34: 15-40.

Jiménez, Catalina. 2014. «El caso del páramo de Santurbán: Accountabilty social exitoso», Revista Zero 32: 10-20.

Leff, Enrique, 2002. «La geopolítica de la biodiversidad y el desarrollo sustentable: economización del mundo, racionalidad ambiental y reapropiación social de la naturaleza». Debates 17: 203-233.

Mayorga, Fernando. 2013. «Democracia intercultural y representación política en las autonomías departamentales e indígenas», en L'Âge d'or. Images dans le monde ibérique et ibéricoaméricain 6: 1-13.

Ministerio del Ambiente de Ecuador. 2012. Sistema de clasificación de los Ecosistemas del Ecuador Continental. Quito: MAE.

Morales-Betancourt, Juan y Jaime Estévez. 2006. «El páramo: ¿ecosistema en vía de extinción?», Revista Luna Azul 22: 15-35.

Mulet, Caridad e Isabel Castanedo. 2002. "La participación comunitaria y el medio ambiente». Revista Cubana de Enfermería 2: 1-20.

Niembro, Roberto. 2013. "Una mirada al constitucionalismo popular», Isonomía 38: 191-224.

Olmos, Juan David. 2018. "Colombia: los miedos que genera la delimitación del páramo de Pisba». Semana Sostenible, 24 de septiembre. Acceso el 17 de octubre de 2019. https://es.mongabay.com/2018/09/paramo-de-pisbaproblema-social-colombia/ 
Pérez, Carlos, Lilia Zizumbo y Miguel González. 2009. «Impacto ambiental del turismo en áreas naturales protegidas; procedimiento metodológico para el análisis en el Parque Estatal El Ocotal». Revista El Periplo Sustentable 16: 20-40.

Quijano, Aníbal. 2000. «Colonialidad del poder, eurocentrismo y América Latina», en La colonialidad del saber: eurocentrismo y ciencias sociales. Perspectivas latinoamericanas. Buenos Aires: CLACSO-UNESCO.

Rodríguez, Adriana. 2017. El largo camino del Taki Unkuy. Los derechos lingüisticos y culturales de los pueblos indígenas del Ecuador. Quito: Huaponi.

Semana Sostenible. 2018. "Los 9 municipios que le dijeron No a la minería usando la consulta popular», Semana Sostenible, 12 de octubre. Acceso el 17 de octubre de 2019. https://sostenibilidad.semana.com/medioambiente/articulo/los-9-municipios-que-le-dijeron-no-a-la-mineria-usandola-consulta-popular/41872

Serrano, David y Remigio Galárraga. 2015. «El páramo andino: características territoriales y estado ambiental. Aportes interdisciplinarios para su conocimiento», Estudios geográficos 76, n. ${ }^{\circ} 1278$ : 10-30.

Surrallés, Alexandre. 2009. "Entre derecho y realidad: antropología y territorios indígenas amazónicos en un futuro próximo». Bulletin de I'Institut français d'études andines 38: 18-38.

Tapia, José. 2019. «Extractivismo en Ecuador. ingreso económico y derechos de la naturaleza», Cálamo, Revista de Estudios Jurídicos 11: 38-51

Trujillo, Carmen, José Moncada, Jesús Aranguren y Kennedy Lomas. 2018. «Significados del agua para la comunidad indígena Fakcha Llakta, cantón Otavalo». Revista Ambiente \& Sociedade 21: 20-50.

UNESCO. 2005. Patrimonio mundial en manos de jóvenes. Conocer, atesorar y actuar. París: UNESCO

Walsh, Catherine. 2009. Interculturalidad, Estado, sociedad, luchas (de) coloniales de nuestra época. Quito: Abya Yala-UASB.

Zhagui, Julio y César Ruiz. 2018. "Formas comunicacionales de resistencia indígena campesina frente al Proyecto Minero Kimsakocha en Ecuador», Ciencia e Interculturalidad 23, n. ${ }^{\circ}$ 12: 16-36. 


\section{Copyright}

Deusto Journal of Human Rights / Revista Deusto de Derechos Humanos is an Open Access journal; which means that it is free for full and immediate access, reading, search, download, distribution, and reuse in any medium only for non-commercial purposes and in accordance with any applicable copyright legislation, without prior permission from the copyright holder (University of Deusto) or the author; provided the original work and publication source are properly cited (Issue number, year, pages and DOI if applicable) and any changes to the original are clearly indicated. Any other use of its content in any medium or format, now known or developed in the future, requires prior written permission of the copyright holder.

\section{Derechos de autoría}

Deusto Journal of Human Rights / Revista Deusto de Derechos Humanos es una revista de Acceso Abierto; lo que significa que es de libre acceso en su integridad inmediatamente después de la publicación de cada número. Se permite su lectura, la búsqueda, descarga, distribución y reutilización en cualquier tipo de soporte sólo para fines no comerciales y según lo previsto por la ley; sin la previa autorización de la Editorial (Universidad de Deusto) o la persona autora, siempre que la obra original sea debidamente citada (número, año, páginas y DOI si procede) y cualquier cambio en el original esté claramente indicado. Cualquier otro uso de su contenido en cualquier medio o formato, ahora conocido o desarrollado en el futuro, requiere el permiso previo por escrito de la persona titular de los derechos de autoría. 